Stewart, Practical Medicine. Lectures at 5 P.M. : February 20, Mr. Etherington Smith, Clinical Lecture II.; February 21, Dr. Pritchard, Practical Medicine ; February 22, Mr. Lloyd Williams, "Oral Conditions in their Relation to General Conditions of Health and Disease" ; February 23, Mr. Baldwin, Practical Surgery ; February 24, Mr. Rickard Lloyd, Anæsthetics.

THE following are the arrangements for next week at the Medical Graduates' College and Polyclinic, 22 Chenies Street, W.C. : Monday, February 20, at 4 P.M., Dr. J. M. H. MacLeod, Clinique (Skin); at 5.15 r.м., Dr. H. D. Rolleston, "Some Aspects of Lymphadenoma." Tuesday, at 4 P.м., Dr. J. J. Perkins, Clinique (Med.) ; at 5.15 P.м., Mr. Arthur Edmunds, "The Surgical Treatment of Tumours of the Breast." Wednesday, at 4 P.M., Mr. F. C. Wallis, Clinique (Surg.); at 5.15 P.M., Dr. W. H. Kelson, "Some Common Affections of the Ear" (illustrative cases). Thursday, at 4 P.M., Dr. Theodore Thompson, Clinique (Med.) ; at 5.15 P.м., Dr. William Hill, "Demonstration of a New Method, combining Direct and Indirect Gastroscopy." Friday, at 4 P.M., Mr. Ernest Clarke, Clinique (Eye).

\section{EDITOR'S LETTER-BOX.}

\section{PIT PONIES.}

To the Editor of The Hospital.

Sir,-With reference to the letter on this subject in your issue of the 21st Jan., I should be glad if you would allow me to place before your readers the proposed restrictions and regulations for effecting a reform of the present reatment and condition's of pit ponies which I tendered to the Royal Commission on Mines at my examination on the 12th, 13th and 19th July :-

1. The numbering of every animal on descending the shaft.

2. No animal to be engaged. under or over a certain age.

3. Limitation of hours of ponies' work.

4. A meal midway between the aliotted hours of work.

5. Supply of water for every animal engaged.

6. Every driver to be licensed and registered and the time during which he is in charge of a specified animal booked to him.

7. Every injury to a pony to be reported, investigated, and registered.

8. Periodical examination of all animals by veterinary surgeons appointed by Government, and invested with plenary powers.

These suggestions are based on the consensus of the opinions expressed by the miners who have been giving us their essential evidence and assistance in this work.

I would desire to point out that we are fully aware that some of them are at present voluntarily included in the "Special Rules" observed at various collieries, and that their legal adoption and enforcement would not in the least degree affect the collieries at which the well-being of the animals employed is considered, but would certainly preclude the perpetration of deliberate or necessitated cruelty by the remainder. The number and extent of these latter is the question which is the main consideration. But whatever facts may be elicited, our contentions are plain and decided. At the present time animals in mines ewe their sole protection to these perfunctory "Special Rules" which may be suggested by the colliery management; the human workers are protected in their work by the most precise and circumspect code of regulations that can be devised by the wit of man, legally enacted, universally applied, and stringently enforced. We desire to put the claims of the dumb worker on a legislative level with those of the human, and by identical means. This duty should not be entrusted to the R.S.P.C.A., to any other society, or even to the National Equine Defence League. As a national, social, and moral obligation, its realisation should be effected by the nation, through the nation's appointed officers, and most certainly not by private charity. Societies die-or should-of their own success, and are to a very large degree dependent for their efficiency on the character and inclinations of their paid officials (whose hearts may-or may not-be in their work), who have to conform to the whims and prejudices of a committee, and who, moreover, may exploit the cause as a basis for eliciting public money. As a nation, we have no right to ask or expect a small section of the public to burden themselves with the execution of a duty which is incumbent upon us all.--Yours faithfully,

National Equine Defence League, Francis A. Cox,

27 Beaconsfield Road, New Southgate, London, N.

\section{TURIN INTERNATIONAL EXHIBITION 1911. THE BRITISH SECTION.}

Sir,-It has been decided that in the British Section of the approaching Turin Exhibition, chemical and physical apparatus shall be shown as far as possible in a truly practical and novel manner; and I trust you will afford me through the medium of your valuable columns an opportunity of giving information to the public regarding the scheme.

Generally speaking, no means are provided at exhibitions for demonstrating the utility of the instruments exhibited; and it has been felt that it would be a very great improvement to show apparatus as it would be used in a laboratory. Accordingly, for the British Chemical Section of the Turin Exhibition arrangements are now upproaching completion by which, it is anticipated, there will be on view at least two well-equipped chemical laboratories, with such work going on as will effectively illustrate var:ous interesting processes. In addition, there will be a large space available for the display in showcases of chemical products and apparatus not in use in the laboratories. Smaller rooms will be provided for certain special appliances. The Court devoted to Scientific Instruments will be of s.milar cesign. Here also arrangements are being made for the display of apparatus ready for work, electric supply, where needed, being provided. The equipment of a large dark-room is under consideration, and in this projection-apparatus, such as oscillographs, spectroscopes, optical lanterns, and photometers could be shown to advantage. The organisation of the exhibits referred to has been placed by the Exhibitions Branch of the Board of Trade in the hands of Dr. F. Mollwo Perkin, under the direction of a joint SubCommittoe of the Chemical Industries Committee and the Mathematical and Scientific Instruments Sub-Committee. Th's joint Sub-Committee considers that exhibitors could not have more favourable conditions for demonstrating. the merits of their exhibits than those which this new arrangement will afford, and that at the same time in the way of instruction by such demonstrations the visiting public will be greatly bcnefited.--Your obedient servant,

Boverton Redwood,

Chairman Chemical Industries Committee.

Board of Trade

(Exhibitions Branch), Feb. 2. 